ISSN 00156043

\title{
EDITORIAL
}

\section{Regeneración ética y compromiso político para una sociedad democrática avanzada}

\section{Consejo de Redacción}

Resumen: El comentario reflexiona sobre la responsabilidad política en el deterioro del sistema democrático e intenta contribuir a la regeneración ética del mismo. Puesto que la comunidad universitaria ha de jugar un papel esencial en la búsqueda y el diálogo que conducen a esa regeneración responsable, hemos de subrayar el papel de la educación cívica y política de los estudiantes universitarios para capacitarles en el ejercicio de ese arte como servicio al bien común.

En el comentario partimos de la actual situación española de quiebra democrática y de deslegitimación de los partidos y de la "clase política" en su conjunto. La pregunta por la democracia representativa, en este momento en que muchos cuestionan los consensos constitucionales, es incisiva e inquietante. El editorial aborda también el análisis de la deslegitimación del sistema democrático y hace algunas propuestas para la regeneración democrática de nuestra sociedad, a partir de una cultura política de una democracia de calidad, impregnada de valores.

Palabras clave: bien común, consensos constitucionales, "herejía emocional”, partidos políticos, quiebra democrática, sociedad democrática avanzada, postdemocracia, responsabilidad social.

Fecha de aprobación: 25 de abril de 2013 


\section{Ethical Regeneration and political commitment in an advanced demo- cratic society}

Abstract: The comment reflects on political responsibility in the deterioration of the democratic system and seeks to contribute to its ethical regeneration. Since the university community must play a key role in the search and dialogue that will lead to this responsible regeneration, we place great importance on the role of civic and political education for college students to train them in the exercise of this art as a service to the common good.

Our commentary starts out in the current Spanish situation of democratic breakdown and the delegitimizing of political parties and the "political class" as a whole. To question representative democracy at this moment in time when many are questioning constitutional consensus is both incisive and disturbing. This editorial also offers an analysis of the delegitimizing of the democratic system and makes some proposals for democratically regenerating our society through a political culture within a democracy of quality, imbued with values.

Keywords: common good, constitutional consensus, "herejía emocional", political parties, democratic breakdown, advanced democratic society, post-democracy, democratic accountability.

\section{Régénération éthique et compromis politique pour une société démocra- tique avancée}

Résumé: Le commentaire est une réflexion sur la responsabilité politique de la dégradation du système politique et il essaie de contribuer à la régénération éthique de celui-ci. Étant donné que la communauté universitaire a joué un rôle essentiel dans la recherche et le dialogue qui mène à cette régénération responsable, nous devons souligner le rôle de l'éducation civique et politique des étudiants universitaires afin de leur faciliter l'exercice de cet art comme un service au bien commun.

Dans ce commentaire notre point de départ est la situation espagnole actuelle de "faillite démocratique» et de délégitimation des partis et de la classe politique dans son ensemble. La question pour la démocratie représentative, au moment où nombreux sont ceux qui contestent les consensus constitutionnels, est incisive et inquiétante. L'éditorial aborde également l'analyse de la délégitimation du système démocratique et fait quelques propositions pour la régénération démocratique de notre société, en partant d'une culture politique d'une démocratie de qualité, imprégnée de valeurs.

Mots clefs: bien commun, consensus constitutionnels, «hérésie émotionelle», partis politiques, "faillite démocratique», société démocratique avancée, post démocratie, responsabilité démocratique. 


\section{Introducción}

Desde un punto de vista político podemos afirmar, como en un sentido más amplio hacía la encíclica Sollicitudo rei socialis, que todos debemos sabernos y ser reconocidos como "responsables de todos" (SRS, n. 38). La comunidad universitaria ha de jugar un papel esencial en la búsqueda, en el diálogo y en la manera honrada de alcanzar y cuidar esta corresponsabilidad y ha de prestar una gran atención a la educación cívica y política de los jóvenes, y entre estos expresamente la de los estudiantes universitarios, para que se inicien en la conciencia y el ejercicio de esa responsabilidad compartida por la vida común. Los ciudadanos podrán así cumplir mejor con su misión en la vida común. Quienes son o lleguen a ser capaces de ejercer "el difícil y noble arte de la política" han de prepararse para el mismo sin estar exclusivamente centrados en el propio interés, en la pretensión de ganar más o en la de de dominar a los demás. La política debe ser ante todo un servicio al bien común.

Contribuir a establecer la justicia, la libertad y la igualdad, promover el bien de todos conforme a un orden económico y social justo y la convivencia democrática de la sociedad plural, asegurar a todos una digna calidad de vida y establecer una sociedad democrática avanzada no son quimeras que puedan ser abandonadas en las cunetas de la historia como un lastre pesado, sino compromisos adquiridos por varias generaciones en la reciente lucha por la democracia y en su desarrollo y el ejercicio de los derechos fundamentales inherentes a la misma. Aquéllos son los únicos ideales movilizadores capaces de hacernos, al vivir juntos, mejores personas y capaces de avanzar hacia una sociedad más justa. Aunque no podemos dejar de plantearnos y discernir qué es irrenunciable y qué no es ya sostenible en el contenido del Estado social, hemos de aceptar también la novedad de una realidad que conlleva que existan otras formas y posibilidades de acción política y se acuerden nuevos consensos básicos para seguir construyendo una sociedad democrática avanzada.

Es probable que, aún más en estos tiempos de crisis, se espere de una revista como la nuestra, realizada en la universidad y desde la tradición de reflexión social de los jesuitas, que favorezca la investigación de soluciones y su proposición ante los retos de la construcción social, que tenemos por delante.' Nos

\footnotetext{
${ }^{1}$ Al igual que en otras ocasiones, este editorial tuvo en su origen un seminario interno del Consejo de redacción que, con una ponencia introductoria, analítica y propositiva, a cargo del profesor Eduardo Moyano, director del IESA-CSIC de Córdoba y miembro de nuestro consejo, que fue el 24 de enero de 2013. Por otra parte, el 10 de julio, con bastante posterioridad a la elaboración y aprobación de este editorial, se presentó en Madrid, un documento de UNIJES Por la regeneración democrática de la vida
} 
sentimos llamados y concernidos por esta expectativa posible y la hacemos nuestra.

En este comentario trataremos, como punto de partida, sobre la llamada "quiebra democrática" $y$, como hecho más relevante, sobre la deslegitimación de los partidos políticos y con ellos de la "clase política" en su conjunto. En este momento muchos se cuestionan los consensos constitucionales y se preguntan si la democracia representativa, que funcionó en Europa aceptablemente bien en el último medio siglo, como sociedad clasista fundada en un pacto social aceptado por las mayorías sociales, sigue siendo adecuada para una sociedad postindustrial y postclasista. En un segundo momento nos detendremos en el análisis de algunos hechos de la realidad política española que, a nuestro juicio, manifiestan una creciente deslegitimación democrática del sistema, siendo al tiempo una de las causas que la explican. En tercer lugar, ensayaremos algunas propuestas para la regeneración democrática de nuestra sociedad. Ante esta quiebra democrática, no podemos cerrar los ojos, pero tampoco apesadumbrarnos o dejarnos deslumbrar por la inmediatez de los hechos. ¿̇Cuál es la responsabilidad de nuestra revista?, ¿̇tenemos una misión propia? Ante la quiebra del sistema, no podemos quedarnos callados. Tampoco queremos. Nos atrevemos a proponer una cultura política impregnada de valores y una democracia de calidad.

\section{Un momento de quiebra democrática}

En tiempos de crisis y de penurias, de desazón y de sufrimiento para muchos, tanto para las personas como para las sociedades, no podemos caer en la desesperanza, ni tampoco debemos desconfiar irracionalmente de la política. El arte de vivir juntos y de pensar juntos la vida común -ésa es nuestra idea de la políitica- nos hace más humanos. La vida común como sociedad, como ciudadanos y como pueblos que comparten espacios, tradiciones e intercambios, exige que rehabilitemos una política digna de ese nombre. Nuestra sociedad ha vivido otros tiempos en que la acción política lograba representar el noble arte de buscar juntos los valores compartidos, de trabajar juntos por el bien común. La sociedad española sabe lo que fue una política al servicio de una mayor justicia, pero hoy los consensos básicos y fundamentales de la vida común parecen cada día más frágiles o están ya rotos. Ciertamente vivimos otros tiempos. Por ello no es ocioso hacer memoria

pública en España, que publicamos integralmente en este mismo número. Además de algunas referencias muy completas en la prensa diaria ( $A B C$, Madrid) y semanal (Vida Nueva), sobre este documento puede verse la breve introducción de Francisco J. Bocero de la Rosa en este mismo número de RFS. 
de experiencias históricas prometedoras o que sirvieron de fundamento de nuestro actual ser político.

Sin nostalgias ni idealizaciones de ningún tipo, queremos desde el comienzo reconocer como experiencia realizada y como ideal, la necesidad de tener una buena política para una sociedad democrática avanzada. Por eso queremos reflexionar conjuntamente con nuestros lectores sobre el significado de una regeneración ética del compromiso político. La lucha por el poder, por conquistarlo y ejercerlo, no es -o al menos no debería ser- el objetivo único o predominante de la política, aunque tener y ejercer poder sea necesario para hacer política y cambiar las cosas. El fin de aquélla debe ser el servicio a la vida común, a la vida de todos y a cada persona humana. Éste es el fundamento y la finalidad de la convivencia política. Del ejercicio de ese servicio que los ciudadanos realizan para fortalecer, preservar y promover esa convivencia, depende que la política sea valorada en su justa medida o denostada generando desconfianza hacia ella.

Existe un progresivo deterioro de la visión sobre la realidad social. Ésta queda reducida, para algunos, a un simple juego de intereses privados. El afán desmedido de lucro y el ansia de poder son una de las causas de la degradación política que experimentamos. La resignación acaba produciendo desinterés por la vida común, que queda abandonada a los simples intereses privados yuxtapuestos. La idea de justicia se desfigura hasta hacerse irreconocible.

¿Cómo podemos reconocer lo que es justo, lo que es debido? La condición humana y la racionalidad-discursiva y cordial, por aludir con estas palabras a pensamientos conocidos como los de Habermas, Apel o Cortina- pueden fundamentar una política al servicio del bien común siempre que se sitúen en un horizonte de verdad, de su búsqueda realizable a través del diálogo y de honradez intelectual.

Diversos actores mundiales llaman continuamente la atención sobre la necesidad de que la política recupere espacio sobre la economía, aquel espacio que le corresponde. ${ }^{2}$ La decisión sobre los fines y los medios para ordenar la vida común y para que las instituciones y las leyes estén al servicio de todos, corresponden al ámbito políitico. En la sociedad global sólo habrá un desarrollo digno para la persona si la política orienta la vida común y regula el papel de la economía. El desarrollo humano sólo es deseable si es integral, es decir de toda la persona y de todas las personas. Para fundamentar este desarrollo hemos de partir -o recuperar,

${ }^{2}$ Cf. el documento del CONSEJO PONTIFICIO JustiCIA Y PAZ "Para una reforma del sistema financiero y monetario internacional en la perspectiva de una autoridad pública con competencia universal": Revista de Fomento Social 66 (2011) 753-771. 
allá donde se hubiese perdido- una auténtica visión de lo humano, un humanismo nuevo. Habrá que buscar y encontrar un difícil equilibrio, aunque sea cambiante, y evitar que la economía "colonice" el mundo político. Pero también habrá que impedir que la primera esté totalmente supeditada a la acción política. Ciertamente conocemos suficientemente bien lo que fue la actuación de "los enemigos de las sociedades abiertas" y cómo en el pasado se intentaron y desarrollaron experiencias de control político de todo lo existente (los totalitarismos, aunque figuren con otros nombres) que no deseamos revivir. Por ello, nuestra propuesta no consiste en que la política ocupe todos los espacios sociales, con el riesgo de diferentes tipos de autoritarismos dictatoriales, populistas o nacionalistas excluyentes, aunque tampoco debamos aceptar una ingenua desregulación económica sin intervención de la política. La libertad, la iniciativa y la autonomía de las personas, los grupos y las comunidades deben ser garantizadas precisamente por el sistema y la acción políticas, pero del control de la economía sólo deberíamos hablar de forma muy matizada, pues cualquier experiencia de control no vale. Defendemos una regulación del mercado al servicio de fines humanizadores, la que ha impulsado Europa con el sistema de Economía Social de Mercado (ESM).

La recuperación del nervio político y de la importancia de la vida común no significa para nosotros una indeseada absolutización de la política, sino algo tan simple pero tan esencial como la primacía del servicio al bien común por encima de lo particular, pues lo que afecta a todos, todos deben decidirlo en el respeto activo hacia las mayorías y las minorías. Hoy sucede precisamente lo contrario: cada día más, no sólo los más ricos son mucho más ricos, aumentando la distancia con los pobres, inmensa mayoría planetaria, sino que cada vez menos personas toman decisiones sobre las mayorías, incluso sobre todos, muchas veces sin participación ni control democrático de instituciones auténticamente representativas. Es cierto que las distancias entre rentas y grupos sociales no sólo siguen siendo territoriales y mundiales, sino que sobre todo hoy se establecen dentro de las mismas sociedades y Estados. La pobreza ha pasado a ser no sólo un fenómeno mundial norte-sur, sino una fractura en el seno de muchas sociedades. En este contexto, probablemente el espacio europeo no sea sino una excepción privilegiada de cohesión y de solidaridad social, aunque no la idealicemos sin más y esté sufriendo un progresivo deterioro.

Todos deberíamos tener garantizado el acceso al control de los poderes públicos y de sus decisiones. Por otra parte, también aquellas decisiones, aunque estén legítimamente tomadas en ámbitos de la vida privada o de la iniciativa social, que nos afecten a todos, deben tener formas de control democrático $y$, en todo caso, de responsabilidad social y de transparencia. Hay un clamor imparable aue va creciendo en este sentido. Obviamente la democracia directa es imposible 
en las actuales sociedades masificadas y complejas; tampoco proponemos una democracia simple de movimientos sociales sin articulación política representativa, pero el avance hacia modelos más "republicanos" (participativos y deliberativos) nos parece imparable. Se trata, a nuestro juicio, de la línea más plausible para resolver la llamada "quiebra democrática" de los actuales modelos burocratizados y "colonizados" por opacos grupos de interés.

\section{Algunas notas para un análisis de nuestro actual momento político}

La crisis de la política no es exclusiva, ni principalmente, española. Por otra parte, en nuestro país hay factores específicos más graves que en otros sitios: la corrupción más extendida, la gravedad de la crisis económica por las deficiencias estructurales del sistema productivo, unida al "déficit" de calidad y de productividad del sistema educativo y de un modelo laboral excesivamente rígido, la debilidad cultural del sistema de partidos políticos, garantes del pluralismo y la participación políticos y, por último, la incapacidad para lograr consensos, una cuestión especialmente grave para la reforma constitucional del modelo territorial.

Parece que ya casi nadie pone en duda que la llamada clase política se ha distanciado de la sociedad civil. La desconfianza en la clase política ha generado una desconfianza creciente en el sistema democrático. Éste resiste, pero, ¿̇por cuánto tiempo? Muchos hablan de consensos irremediablemente rotos.

Nos preguntamos -esperamos que no sea de modo retórico- si, con la presente desafección hacia la política como actividad, a la elite política como clase y al sistema político democrático, el Estado social y democrático de derecho puede seguir siendo viable si antes no acometemos con claridad y energía las reformas necesarias. Con nuestra pregunta no nos gustaría inducir una respuesta negativa; sólo pretendemos vigorizar la necesidad urgente de una propuesta creativa y radical ante la emergencia democrática.

Con el paso de una sociedad de clases e industrial, basada en un pacto social articulado en torno a tres consensos -social-demócrata, social-liberal y socialcristiano-, a una sociedad postindustrial e individualista, el modelo de Estado social es fuertemente cuestionado en su fundamentación y en su viabilidad. Ni aquél puede ser considerado indiscutible, ni puede ser banalizado como mero accidente histórico. A este Estado social le faltan los soportes culturales, sociológicos y éticos para hacerlo viable a corto plazo y sostenible a medio plazo. Por 
otro lado el neoliberalismo, imperante y aparentemente triunfante, se basa en la exaltación del individuo y la ignorancia del bien común y del principio de justicia. A los defensores del mismo les cuesta entender lo social-estructural, pues reducen la sociedad a la suma de individualidades.

Tras la segunda guerra mundial, originada en nuestro continente, la muerte de millones de personas en el campo de batalla, pero sobre todo en la retaguardia, por tanto de población civil, y lo que marcaría para siempre el futuro de la cultura europea, el intento de aniquilamiento del pueblo judío con seis millones de muertos, en Europa se abrió paso una nueva época. En el contexto mundial posterior a la segunda guerra mundial, con los Derechos humanos reconocidos como base civilizatoria y normativa, la economía keynesiana y la guerra fría, se produjo un pacto social que dio lugar a las llamadas constituciones políticas de la posguerra y a la economía social de mercado. ${ }^{3}$ Este pacto social hacía converger a la burguesía de tradición liberal defensora del Estado garante del mercado, con las clases populares de extracción agraria o menestral y de clase media presente en el llamado mundo "popular", de fuerte pertenencia cristiana, y con la clase obrera industrial representada por los sindicatos y los partidos obreros.

Frente a aquella Europa que ha llegado casi a nuestros días, tal como se concibió hace unos sesenta años y se fue construyendo, sobre todo, hasta mediados de los años 90 , hoy nos encontramos con una realidad social cada día más polarizada tanto en la distribución de la renta, repartida crecientemente de forma desigual, como en el apoyo al sistema político. El grito de "no nos representan" no sólo incluye una queja ante la corrupción política o económica de nuestra "clase política", sino el rechazo a los habituales comportamientos de ésta alejados de la ciudadanía.

La actual fractura de la comunidad o "cuerpo político" reviste gran importancia en dos ámbitos. Por un lado el modelo de Estado, que Europa ha conocido desde mediados del siglo XVII, basado en la soberanía nacional y territorial. A partir de 1950 Europa comenzó un decidido proceso de Unión supraestatal de corte federal que ahora ha entrado en un momento de crisis profunda. Por otro lado, la progresiva integración europea no se está conformando hoy como una forma federal de gobierno, protagonizada por unos actores democráticamente elegidos y controlados, sino como el gobierno de ciertas élites fuera de todo control. Algunos gobiernos de países hegemónicos ejercen un importante influjo en otros Estados diferentes al suyo, o sobre las autoridades monetarias y los bancos centrales, etc. Este influjo condiciona un auténtico ejercicio democrático en la Unión Europea,

${ }^{3}$ Cfr. nuestro editorial "Un sistema de economía social de mercado para una Europa solidaria, responsable y productiva": Revista de Fomento Social 68 (2013) 5-29. 
aún cuando el Parlamento europeo emane de la ciudadanía y la Comisión y el Consejo nazcan de gobiernos en todo caso democráticos.

No debe extrañarnos que haya crisis en Europa: ésta es parte sustancial de nuestra manera de entender el proceso de integración y construcción de ese espacio privilegiado de esperanza para la humanidad que querríamos ser $y$, en buena medida, somos. Por otro lado, en Europa hoy son cuestionadas las construcciones estatales de forma insistente y a veces con cierta virulencia: ahí están Escocia, dentro del Reino Unido, Flandes en Bélgica, el norte italiano en aquella República, Cataluña o el País Vasco en España, por no referirnos a la desmembración nada lejana de partes importantes de la Europa eslava. No podemos ignorar estos hechos, aunque la interpretación de los mismos no sea objeto de este comentario. El "cuerpo político" aparece hoy en Europa en convulsión hacia arriba y hacia dentro. Aceptar que caben otras formas de configuración del mismo no significa que este momento sea fácil de interpretar ni de gobernar, puesto que hasta ahora los mecanismos de control democrático a los que estábamos habituados, eran los ejercidos en el marco de los Estados territoriales. Esto parece que se está acabando, pues la ciudadanía no se resigna, se indigna, protesta y finalmente puede votar diferentemente de lo que pretenden las élites gobernantes europeas; así ha ocurrido en Grecia y más recientemente en Italia.

Por otra parte, existe una realidad social enfrentada con amplios sectores de exclusión: nuevos pobres (los conocidos en ámbito anglosajón como "working poors"), personas que aun teniendo empleo, no dejan de ser pobres, y clases medias en declive que ven amenazadas sus expectativas, pues el "ascensor social" ya no funciona. La sociedad, cada vez más fragmentada en la Europa a dos velocidades, no se siente representada por sus élites y ha roto afectivamente con ella. Se trata de una manifestación de lo que en sociología del conocimiento se denominó, hace ya unos años, "herejía emocional".

En buena medida, nuestra experiencia actual de la democracia la estamos haciendo a partir de las expectativas que teníamos puestas en ella hace treinta o más años. Cuando parece que muchos ya no esperan nada del sistema democrático, procede hablar de "herejía emocional" para referirnos a aquella actitud emotiva y mental de quien ha perdido toda confianza y toda esperanza de recibir ninguna buena noticia del entramado de creencias e instituciones en que sigue sustentando su vida. En el estado de "herejía emocional" no se cuestionan -todavía- las creencias, ni siquiera los valores. Se dan simplemente por supuestos y quizá por válidos, pero de hecho ya no se espera de ellos nada que pueda ayudar a configurar la propia vida. Muchos ciudadanos españoles viven -o vivimos- esta "herejía emocional" en relación a la democracia. Siguen siendo demócratas, pero ya no sintonizan 
aquella frecuencia desde la que se alimentan sus convicciones o institucionalizan las correspondientes prácticas de sentido, pues sencillamente no encuentran nada en ellas que les sirva realmente para sus vidas. Lo que está pasando en la vida pública, atravesada de un amplio malestar, se parece mucho a esta llamada "herejía emocional". Miramos desde la perplejidad a muchos "indignados" que han llenado nuestras plazas y avenidas desde hace dos primaveras: han tenido el coraje suficiente de decir "hasta aquí hemos llegado" y reaccionan entre atónitos, airados y desorientados ante un progreso individual que de golpe ha quedado truncado. Para los muchos aquejados de "herejía emocional" o para los "decepcionados" urge una propuesta política que devuelva el valor al tiempo y a la palabra. Al tiempo, para enseñar, aprender, aceptar e interiorizar que lo valioso sólo se consigue con el paso de aquel tiempo consagrado a transformar interiormente nuestro ser al mismo ritmo y en el mismo sentido en que transformamos la realidad circundante; a la palabra, devolviéndole su dignidad de intérprete de nuestro amor por este mundo. No tenemos otro mundo al que podamos confiar nuestro esfuerzo mejor que éste, al que amamos apasionadamente, aunque soñemos un mundo radicalmente otro.

El desprecio hacia la clase política se considera el problema principal de la democracia española. En un año, según el barómetro del CIS de enero de 2013, la "clase política" y la corrupción han pasado a ser uno de los tres problemas principales de la sociedad para el $17,7 \%$ y para $30,3 \%$ de los españoles, respectivamente, mientras un año antes lo era sólo para el $3,2 \%$ y el $6,6 \%$. El deterioro producido ha sido enorme. Junto a una "clase política" endogámica y autorreferenciada en sus intereses reproductivos, a la que algunos autores señalan como élite extractiva, nos encontramos con la apatía inactiva de las élites empresariales-financieras. En el deterioro del éthos político español y en su percepción ciudadana nos parece que la corrupción es el hecho más determinante de esa pérdida ética.

El diagnóstico es común a ambas: están distanciadas de la sociedad civil, y abocadas al colapso y a la generalización del desprecio de la clase política.

La desigualdad social, que todos los estudiosos señalan como algo creciente desde mediados de los 80 en toda Europa, y más fuerte en España, especialmente en los últimos seis años, está provocando el eclipse de la clase media con el riesgo de una fractura social sin precedentes, muy diferente a la de los años 30 , por lo que es difícil la comparación. El Estado social y democrático de derecho y la economía social de mercado, como hemos afirmado, se construían a partir de tres consensos interclasistas, pero con un soporte creciente en las clases medias. Si las clases medias están en declive ¿qué cabe mantener de un sistema que se apoyaba en ellas? No podemos dejar de hacernos esa pregunta. El debilitamiento de aquéllas y, a más 
largo plazo, su declive puede provocar que desaparezcan quienes estén dispuestos a sostener este consenso básico sobre el Estado y la economía de mercado.

En su lugar, rompiendo con la cohesión social que ha configurado nuestro sistema en el último largo medio siglo, ha aparecido un modelo individualista que favorece el darwinismo social. La afirmación es simple y simplista: no existe la sociedad, existen los individuos. Tenemos ante nuestros ojos las consecuencias de tal visión: ruptura de la solidaridad, debilitamiento del consenso social, corrupción del lenguaje público. A partir de ahí han crecido la desconfianza, el desafecto y finalmente el riesgo del populismo, y con él de los racismos, radicalismos de extrema derecha y grupos o sectores anti sistema. Nos encontramos entre dos monstruos a cada lado del estrecho: Escila, una democracia senil, y Caribdis, unos jóvenes hijos de la bonanza en "tiempos líquidos". Escila y Caribdis, monstruos marinos de la mitología griega, están situados tan cerca uno del otro que quienes intentan evitar a Caribdis pasan muy cerca de Escila y viceversa. Sin embargo, tras el llamado 15-M la brecha entre las formas convencionales de hacer política y las innovadoras se ha agrandado, con un nuevo peso para la sociedad civil. En este giro surgen las reflexiones finales que siguen.

\section{Ante la deslegitimación democrática: reflexión y propuestas}

Intentamos presentar una reflexión sobre las consecuencias de la quiebra democrática, y en particular sobre los valores del sistema de partidos. Nos hemos hecho algunas preguntas: ¿qué debe ser la democracia como forma de vivir en sociedad?, ¿por qué existe este desinterés por la política?, ¿̇hay factores objetivos para replantear el sistema de partidos? En ese contexto podemos hacernos la pregunta sobre la viabilidad y la conveniencia de ir más allá de la democracia partidista. Siempre se entrecruzarán en este debate dos visiones alternativas: una -más mecánica institucional- confía en el cambio de las leyes, otra -más culturallo hace en el cambio de las mentalidades. La crisis actual pone de manifiesto un nuevo equilibrio aún no logrado entre carisma, liderazgo y redes como la forma de la acción políitica, en un tiempo en que asistimos a la emergencia de una nueva sociedad civil con nuevos enfoques de gobernanza global y con exigencias de una democracia de calidad.

Una primera pregunta surge: si la crisis de la política se debe a los partidos políticos, ¿hay factores objetivos para replantear el sistema de partidos? Sabemos que la crisis es también responsabilidad y consecuencia de actitudes, trayectorias 
y comportamientos de los actores políticos, especialmente de los gobernantes y de otros actores políticos muy relevantes, pero aún siendo conscientes de este claro componente personal, hemos de reconocer que el desorden ha cristalizado en las instituciones y, en particular, en los partidos políticos endogámicos. Nos encontramos ante el problema con dos actitudes. Para unos es mejor no poner todo "patas arriba", sino ir dando pasos en pro de una superación paulatina de la situación, por ejemplo con una nueva ley de partidos y un nuevo sistema electoral. Los que así piensan, creen que hace falta una segunda transición: primero se deberían lograr unos nuevos "pactos de la Moncloa", para abordar después una reforma constitucional coincidiendo con las elecciones generales de 2015.

Para otros, se trataría más bien de promover un cambio de paradigma de democracia representativa e ir más allá de la democracia partidista, pues lo que está en crisis es la teoría elitista de la democracia: ni el carisma ni el liderazgo tradicional tienen ya efectos en sociedades muy complejas y desarticuladas jerárquicamente. Hoy tanto los individuos, sobre todo los individuos, como los grupos sociales se articulan horizontalmente en redes no jerárquicas por las que circulan las demandas de satisfacción de necesidades. Estamos en momento de emergencia para el sistema democrático ante una nueva sociedad postindustrial configurada por el individualismo, la utilización de las nuevas tecnologías de la información y la comunicación (las llamadas TIC) y la afirmación de la subjetividad por encima de la vinculación social.

Para quienes nos hallamos en una sociedad postdemocrática que combina buenas dosis de populismo con una gobernanza limitada de las élites económicas y tecnocráticas, la apuesta por una democracia de calidad frente a la crisis es la única posibilidad sólida de regeneración que podemos hacer. ¿2Podrá recuperar una sociedad como la nuestra una democracia de calidad? Dicho con otra expresión: ¿podrá ser una sociedad democrática avanzada de calidad? La simple formulación no puede quedar en un "wistful thinking" que de hecho indicaría nuestra incapacidad para asumir la radicalidad y profundidad de la crisis. La solución, ¿consiste en volver a lo de antes? ¿¿Qué democracia podemos recuperar? ¿̇Sólo la de los partidos?

Para quienes creen que no hay política posible desde la afirmación absoluta del individualismo, sólo cabe transitar los caminos para un nuevo contrato social y recuperar la noción de bien común frente a bien total como suma de bienes individuales.

Ante un deterioro continuo y sin retorno del sistema democrático, es urgente un cambio de tendencia. Para avanzar hacia una regeneración democrática habre- 
mos de convertir en hábito saludable y durable lo que nos hace más personas y mejores ciudadanos. La regeneración democrática consiste en trabajar juntos para recuperar una ética pública a partir del capital social aún disponible. Podríamos ver las dificultades o las aporías en que este proceso se sitúa, pero preferimos ver las posibilidades, los caminos transitables. Estas son nuestras propuestas para la regeneración democrática de nuestra sociedad. Ante la situación de crisis o quiebra democrática que hemos descrito, no queremos cerrar los ojos, ni tampoco dejarnos deslumbrar por la inmediatez de los hechos por muy impresionantes que nos parezcan.

La ética pública consiste en gestionar con responsabilidad los recursos y las aspiraciones cívicas, adecuando los medios a los fines, y hacerlo con aquella justicia que debe ser la virtud cívica que impregne toda la ética pública. Esta ética de la justicia debe ser criterio de discernimiento y de ordenamiento de todos los actores políticos en su servicio al bien común.

En un mundo en progresiva y expansiva globalización en que existe una interdependencia de hecho entre los hombres y los pueblos que no se corresponde con la interacción ética de la conciencia y el intelecto, "el amor en la verdad" -por usar una expresión familiar a muchos de nuestros lectores acuñada en el documento papal Caritas in veritate (2009)- es el gran desafío que tenemos para acompañar e impulsar un desarrollo realmente humano, más humano y más humanizado. Para compartir los bienes y recursos necesitamos no sólo progreso técnico o formas que permitan la simple conveniencia, sino aquella capacidad de vencer al mal con el bien que abre la conciencia de las personas a relaciones recíprocas de libertad y responsabilidad. Este debería ser el eje de la formación básica de los estudiantes universitarios.

En este momento queremos apuntar algunas vías de respuesta, que no propuestas, aunque no lleguemos a valorar su viabilidad y oportunidad. Ya no basta el cambio de estructuras, hay que cambiar las prácticas. Ya no basta la reforma institucional, hay que reconstruir la confianza tendiendo puentes entre la sociedad civil y las instituciones representativas. Ya no basta una remoralización interna de éstas, hay que aceptar nuevas formas y lugares para la acción política.

Desde los dos lugares sociales en los que se sitúa Revista de Fomento Social -la universidad y la Iglesia- no tenemos soluciones técnicas que ofrecer ni pretendemos mezclarnos con la tarea propia de la política. Pero tanto la Iglesia como la universidad tienen una "misión de verdad" que cumplir en todo tiempo en favor de una sociedad a medida del hombre, de su dignidad y de su vocación de la que no sabemos ni queremos abdicar. Sin confiar en la posibilidad de acceder a la 
verdad se cae en una visión empirista y escéptica de la vida, incapaz de elevarse sobre aquella praxis que no está interesada en tomar en consideración aquellos valores desde los que es posible orientarla. Esta misión de verdad es irrenunciable para nosotros.

Para que esta afirmación no pueda ser malinterpretada quisiéramos recordar un principio hermenéutico básico que compartimos:

La verdad sólo puede desarrollarse en la relación con el otro que se abre a Dios, el cual quiere manifestar su propia alteridad en y a través de mis hermanos humanos. Por tanto, no conviene afirmar de manera excluyente "yo poseo la verdad». La verdad no es posesión de nadie, sino siempre un don que nos llama a un proceso que nos asimile cada vez más profundamente a la verdad. La verdad sólo puede ser conocida y vivida en la libertad; por eso, no podemos imponer la verdad al otro; la verdad se desvela únicamente en el encuentro de amor. ${ }^{4}$

Para no desentendernos de los deberes de la fraternidad y de la solidaridad y para que el pensamiento oriente adecuadamente el deseo, queremos, como proponía Pablo $\mathrm{Vl}$ y repitió Benedicto $\mathrm{XVI}$, que haya "pensadores de reflexión profunda» que busquen un "humanismo nuevo», que permita al hombre y a la mujer de hoy hallarse a sí mismos, y que haya fraternidad entre los hombres y entre los pueblos. Sabemos que la razón, por sí sola, es capaz de aceptar la igualdad entre los hombres y de establecer una convivencia cívica entre ellos, pero no consigue fundar totalmente la fraternidad que nace de un humanismo nuevo e integral. Buscamos junto a otras personas de nuestro tiempo lograr una nueva síntesis humanista a partir de un amor inteligente, de una verdad compadecida, de una fraternidad reflexiva.

Las fuerzas técnicas, las interrelaciones planetarias, una actividad financiera mal utilizada y en buena parte especulativa, con efectos negativos sobre la economía real, los flujos migratorios, frecuentemente provocados y después no bien gestionados, o la explotación sin reglas de los recursos de la tierra, nos inducen hoy a reflexionar sobre las medidas necesarias para solucionar problemas que tienen

\footnotetext{
${ }^{4}$ Aunque en un contexto diferente y referida al diálogo interreligioso, parece útil la afirmación citada de un reciente documento del magisterio. Cfr. Exhortación apostólica postsinodal Ecclesia in medio oriente, de BENEDICTO XVI (14-IX-2012) Sobre la Iglesia en Oriente medio, comunión y testimonio (n. 27), publicado tras la asamblea especial del Sínodo de los Obispos (10 a 24-X-2010). En el párrafo inmediatamente precedente al citado se dice: Es preciso pasar de la tolerancia a la libertad religiosa. Este paso no es una puerta abierta al relativismo, como algunos sostienen. $Y$ tampoco una medida que abre una fisura en el creer, sino una reconsideración de la relación antropológica con la religión y con Dios. No es un atentado contra las "verdades fundantes» del creer, porque, no obstante las divergencias humanas y religiosas, un destello de verdad ilumina a todos los hombres. Bien sabemos que, fuera de Dios, la verdad no existe como un "en sí». Sería un ídolo.
} 
un efecto decisivo para el bien presente y futuro de la humanidad. La crisis económica, causa y efecto de la crisis del sistema político, requiere también una nueva síntesis humanista. Hay una circularidad entre la ordenación de la economía y la capacidad de respuesta del sistema político.

Por otra parte, la complejidad y la gravedad de la quiebra democrática en la sociedad española nos lleva a asumir con realismo, confianza y esperanza las responsabilidades que nos reclama esta situación. Una profunda renovación cultural y de los valores y consensos prócticos sobre los cuales contribuir a una sociedad democráticamente avanzada, por referirnos a la expresión acuñada en el preámbulo de nuestra Constitución de 1978, para que aquélla sea gobernada y liderada con acierto. La crisis mundial económica y cultural nos obliga a revisar nuestro camino, la crisis política española nos urge a encontrar nuevas reglas y nuevas formas de compromiso, a apoyar las experiencias positivas y a rechazar las negativas. De este modo, la crisis se convierte en ocasión de discernir y proyectar de un modo nuevo.

En resumen, creemos que más allá de los cambios institucionales o morales, hay algo que sí podemos acometer juntos: nos atrevemos a proponer una cultura política impregnada de valores y un avance en una democracia de calidad frente a la crisis. Creemos que el imperativo categórico de una sociedad democrática avanzada que preside nuestro preámbulo constitucional nos obliga, por lo menos, a proponerlo y a buscar los medios para llevarlo a cabo.

Esta regeneración democrática sólo será posible si los ciudadanos no nos instalamos en la retórica de la simplificación ante las soluciones y exigimos no sólo altura moral a las élites políticas, sino altura intelectual. Por otra parte, aceptando la diferencia de concepciones, no cabe descartar que exista una presión cívica sostenida, con apoyo de amplios segmentos de la sociedad civil, entre ellos dos actores decisivos como las iglesias y las universidades, para una democracia de calidad más participativa y más exigente ante las élites gobernantes. Regeneración moral y reforma institucional son las dos opciones ineludibles y complementarias; podrían plantearse como alternativas, pero no es necesariamente así. Ambas deberían ir acompañadas de una cultura crítica, de fraternidad cooperativa y de reflexión profunda.

Como revista escrita en la universidad, quizá logremos aportar a este debate una investigación y reflexión interdisciplinares. La investigación es un bien público que no debe perder en las lógicas de la privatización y de la promoción del interés particular y la trasferencia de conocimiento y proyección social una de las misiones fundamentales de la universidad; de ahí surge nuestra responsabilidad, 
como revista universitaria, en el servicio del bien común. La responsabilidad social de una institución como la nuestra no debe estar funcionalmente orientada sólo a la formación de cuadros para el mercado o de funcionarios públicos, sino a promover y generar un pensamiento alternativo, capaz de suscitar vocaciones humanas al servicio de la cultura y del bien común. Deberíamos también contribuir a recuperar liderazgo para dirigir una salida de la crisis que no se oriente en cualquier sentido. Para ello nos haría bien una cultura política impregnada de valores. De nuestra responsabilidad surge un compromiso, personal e institucional, por una democracia de calidad frente a la crisis. Esta es nuestra apuesta y nuestra aportación para la regeneración ética y el compromiso político en una sociedad democrática avanzada. 